\title{
The Fermentation of Xylans in the Rumen of the Sheep
}

\author{
BY P. J. HEALD \\ Rowett Research Institute, Bucksburn, Aberdeenshire
}

(Received 26 March 1952)

Marshall (I949), using a technique devised by Gray (1947) of estimating the carbohydrate: lignin ratios in samples from the gut of slaughtered animals, determined the quantity of furfural-yielding substances, i.e. pentosans and polyuronides, that disappeared from the rumen of sheep fed on hay. The disadvantages of using a technique that involves measurements on material taken from the rumen have been discussed fully by Hale, Duncan \& Huffman (1940, 1947). These authors pointed out that values so obtained do not indicate the amount of a particular substance digested in the rumen, but merely the amount of that substance that has disappeared owing both to digestion and the normal emptying process of the rumen.

As part of a new study of the digestion of grass hemicelluloses and especially of xylans, which are often the chief constituents of the hemicellulose complex, it was necessary to estimate the amount of these carbohydrates that are fermented in the rumen. For this purpose it was thought preferable to use a method that did not involve measurements on the rumen material, but took into account material leaving the abomasum. Furthermore, instead of using a non-specific analytical method, such as the determination of furfural after distillation of the samples with hydrobromic acid, the constituent sugar, xylose, was determined directly.

\section{EXPERIMENTAL}

\section{Animals and materials used}

Sheep. The sheep used were two Cheviot ewes fitted with both ruminal and abomasal cannulas. The abomasal cannulas were situated caudal to the pylorus and corresponded to cannula no. I described by Phillipson (1952). The animals were maintained on a hay diet fed at intervals of $12 \mathrm{~h}$. The food and water not consumed within $2 \mathrm{~h}$ after feeding were removed. The quantity of hay offered was gradually adjusted until the animals ate all the hay given to them. Under these conditions it seemed reasonable to assume that after a period of 14 days the quantity of food leaving the rumen would bear a constant relation to the amount fed.

Carbohydrates. D-Xylose was a sample from T. Kerfoot Ltd. The sample of esparto xylan was kindly given by Professor E. L. Hirst, University of Edinburgh. It was stated to contain $77 \%$ xylan.

Hay fed. This consisted of the chopped meadow hay normally fed to the animals at this Institute. 


\section{Treatment of the hay before analysis}

Since the material passing to the abomasum had been extracted with water in the rumen in addition to undergoing some fermentation, samples of the hay fed to the sheep were extracted with water at $37^{\circ}$ before analysis. In this way it was thought that the percentage of xylose-containing materials estimated both in the hay fed and in the samples from the abomasum, would be more strictly comparable on a dryweight basis. A known weight of the ground-hay sample was extracted with ten times its weight of distilled water for four periods of $30 \mathrm{~min}$, each extraction being followed by filtration and extensive washing on the filter with water at $37^{\circ}$. The extracted material was dried under diminished pressure at room temperature, and weighed before analysis.

\section{Preparation}

Treatment of samples from the contents of the abomasum

Samples of the material obtained either through the cannulas or from the slaughtered sheep were strained through silk*, and the residues were shaken vigorously in a Microid Flask Shaker with 5 vol. of distilled water for three periods of $5 \mathrm{~min}$, in order to remove as much non-plant material as possible, the samples being strained through silk after each shaking. As will be shown later, this procedure did not cause a loss of plant residues great enough to alter materially the results obtained by using only the strained, washed material for analysis. The residues were dried under diminished pressure at room temperature before hydrolysis.

\section{Analytical methods}

Dry weights. The dry weight of the water extract from the hay samples used for analysis was determined by evaporating the aqueous extract and washings on a steambath. The dry weight of the sediments obtained from the liquid fractions on straining and washing the abomasal samples was determined as follows. The liquid was centrifuged at 6000 r.p.m. in an angle centrifuge (Baird and Tatlock Ltd.) until no further material sedimented. The supernatant liquid was usually quite clear after $30 \mathrm{~min}$. The residues were then combined and washed twice with distilled water in the centrifuge, and finally suspended in a known volume of distilled water. Portions were evaporated at $105^{\circ}$ for determination of dry weight.

Carbohydrate (as xylose). This was estimated by the method of Hagedorn $\&$ Jensen (I923). A standard curve was obtained using D-xylose.

\section{Estimation of xylose-containing material in the water-extracted hay and in the samples from the abomasum}

Weighed samples were hydrolysed for $4 \mathrm{~h}$ with $0.25 \mathrm{~N}-\mathrm{HCl}$ at $100^{\circ}$ in sealed tubes, the tubes being frequently shaken during this period. The seals were then broken, the contents of the tubes adjusted to $\mathrm{pH}_{4.5}$ (Congo red) with silver carbonate and centrifuged. Xylose was estimated by the Hagedorn-Jensen method after paper-

* S. 25 bolting silk (Henry Simon Ltd., Cheadle Heath, Stockport). 
partition chromatography of the supernatant liquids as described previously (Heald, 195 I). The sheets were developed for $72 \mathrm{~h}$ in $n$-butanol saturated with water. Xylose and arabinose were included in the side strips.

The data supporting this procedure are presented in Fig. I and in Tables I, 2 and 3 , and show the essential steps involving: $(a)$ the recovery of xylose after hydrolysis in $0.25 \mathrm{~N}-\mathrm{HCl}$ and $0.5 \mathrm{~N}-\mathrm{HCl}$ (Fig. I); (b) the selection of $3-4 \mathrm{~h}$ as the most suitable

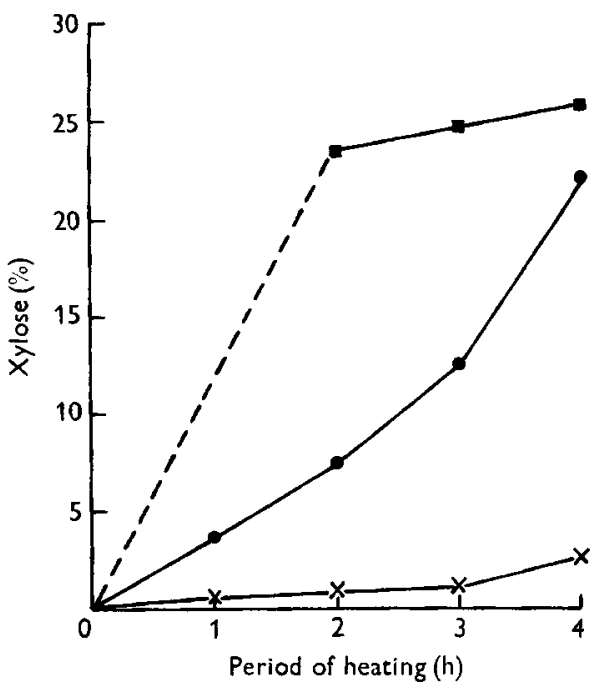

Fig. 1. Production of reducing substances estimated as xylose when water-extracted hay was hydrolysed with $0.25 \mathrm{~N}-\mathrm{HCl}$, and loss of xylose when heated with $0.5 \mathrm{~N}-\mathrm{HCl}$ and with $0.25 \mathrm{~N}-\mathrm{HCl}$. reducing substances produced from hay; -0, loss of xylose when heated with $0.5 \mathrm{~N}-\mathrm{HCl}$; $x \longrightarrow x$, loss of xylose when heated with $0.25 \mathrm{~N}-\mathrm{HCl}$.

period of hydrolysis of hay (Fig. I); (c) the recovery of xylose after hydrolysis in the presence of hay (Table I); $(d)$ the recovery of xylose after paper-partition chromatography from aqueous solutions of xylose and from acid solutions of xylose treated with silver carbonate (Table 2$) ;(e)$ the analysis of a specimen of esparto xylan by the procedure ('Table 3 ).

Table $\mathrm{x}$. Recovery of xylose after treatment with $0.25 \mathrm{~N}-\mathrm{HCl}$ in the presence of hay

\begin{tabular}{|c|c|c|c|c|}
\hline \multirow[b]{2}{*}{$\begin{array}{c}\text { Exp. } \\
\text { no. }\end{array}$} & \multirow[b]{2}{*}{$\begin{array}{l}\text { Amount of } \\
\text { hay taken } \\
\text { (mg) }\end{array}$} & \multicolumn{3}{|c|}{ Xylose } \\
\hline & & $\begin{array}{l}\text { Amount } \\
\text { added } \\
(\mathrm{mg})\end{array}$ & $\begin{array}{l}\text { Amount } \\
\text { recovered } \\
(\mathrm{mg})\end{array}$ & $\begin{array}{l}\text { Gain } \\
(\mathrm{mg})\end{array}$ \\
\hline I & 203.0 & 9.0 & $10 \cdot 5$ & I. 5 \\
\hline 2 & $270 \cdot 2$ & $9 \cdot 0$ & $9 \cdot 4$ & 0.4 \\
\hline 3 & $298 \cdot 2$ & $9 \cdot 0$ & 10.1 & $I \cdot I$ \\
\hline 4 & $272 \cdot I$ & $9 \cdot 0$ & $10 \cdot I$ & $I \cdot I$ \\
\hline 5 & $267 \cdot 8$ & $35^{\circ} \circ$ & $39^{\circ} 6$ & $4 \cdot 6$ \\
\hline 6 & 263.4 & $35^{\circ} \circ$ & $37 \cdot 2$ & $2 \cdot 2$ \\
\hline 7 & $334^{\circ} 0$ & $35 \cdot 0$ & $35^{\circ} \circ$ & 0.0 \\
\hline
\end{tabular}


Table 2. Recovery of xylose after paper chromatography, from aqueous solutions of xylose and from acid solutions of xylose treated with silver carbonate

(Values in $\mathrm{mg} / \mathrm{ml}$.)

$\overbrace{\substack{\text { Xylose } \\ \text { added } \\ 3.55}}^{\text {No treatment }} \underbrace{\text { Treatme }}_{\begin{array}{c}\text { Xylose } \\ \text { recovered } \\ 3.24\end{array}}$

Standard deviation of the mean for sixteen degrees of freedom $= \pm 0.088$

$\overbrace{\begin{array}{c}\text { Xylose } \\ \text { added } \\ 9.45\end{array}}^{\text {Treated with silver carbonate }}$

Standard deviation of the mean for fourteen degrees of freedom $= \pm 0.273$

Table 3. Estimation of the percentage of xylan in a sample of esparto xylan supplied by Professor E. L. Hirst and stated to contain $77 \%$ xylan

\begin{tabular}{cccc}
$\begin{array}{c}\text { Weight of } \\
\text { sample taken } \\
(\mathrm{mg})\end{array}$ & \multicolumn{2}{c}{ Xylose found } & $\begin{array}{c}\text { Xylan in } \\
\text { sample }\end{array}$ \\
$\mathbf{6 4 . 2}$ & $(\mathrm{mg})$ & $(\%)$ & $(\%)$ \\
$6 \mathrm{I} .8$ & 53.1 & 82.7 & 72.8 \\
58.9 & 52.8 & 85.4 & 75.1 \\
& 50.2 & 85.1 & 74.9
\end{tabular}

\section{Plan of the experiment}

The sheep were fed on hay at such a level that all the food was consumed within $2 \mathrm{~h}$ of feeding. Samples of the material leaving the abomasum were collected during the next $2 \mathrm{~h}$, and the percentage of xylose calculated as xylan (xylan $=88 \%$ of the xylose found) was determined in the plant fragments. A similar estimation was made on the hay fed. After establishing the variation (if any) in the percentage of xylan in the material leaving the abomasum during this period, the sheep were slaughtered and the contents of the abomasum were taken for estimation of the total content of dry matter, and of the dry weight of the abomasal juice together with the microorganisms. Since the volume of digesta leaving the abomasum of the sheep is about 5 l. in $12 \mathrm{~h}$ (Phillipson, 1952), and the percentage dry weight of the plant particles in the digesta was known, it was possible to calculate the weight of plant particles leaving the abomasum in $24 \mathrm{~h}$. The calculations for xylan fermented in the rumen were made as follows:

$$
\text { Xylan fermented in the rumen and omasum }(\mathrm{g})=\left(\frac{A \times a}{100}\right)-\left(\frac{B \times b}{100}\right) \text {, }
$$

where $A=$ quantity in $\mathrm{g}$ of hay fed, $B=$ quantity in $\mathrm{g}$ of hay particles leaving the abomasum in $24 \mathrm{~h}, a=$ percentage of xylan in hay fed, and $b=$ percentage of xylan in the hay particles leaving the abomasum.

\section{RESULTS}

The results of such an analysis of two different samples of hay fed to two sheep over a $12 \mathrm{~h}$ period are shown in Fig. 2. With the exception of one result for sheep no. 506 , the quantity of xylan passing from the abomasum formed an almost constant percentage of the plant fragments and corresponded closely to the value found in 
the hay fed. These results were taken to indicate that the percentage of xylan in a sample collected at any one period of the digestion cycle was representative of the values obtaining at other times during that cycle.

In Table 4 is shown the percentage of the ingested xylan fermented in the rumens of the two sheep. It was thought that the quantity of plant particles that passed through the silk when the abomasal samples were being strained might have appreciably affected the results by causing a loss of xylan-containing material. Accordingly the percentage of xylan was estimated in the sediment that could be centrifuged from the

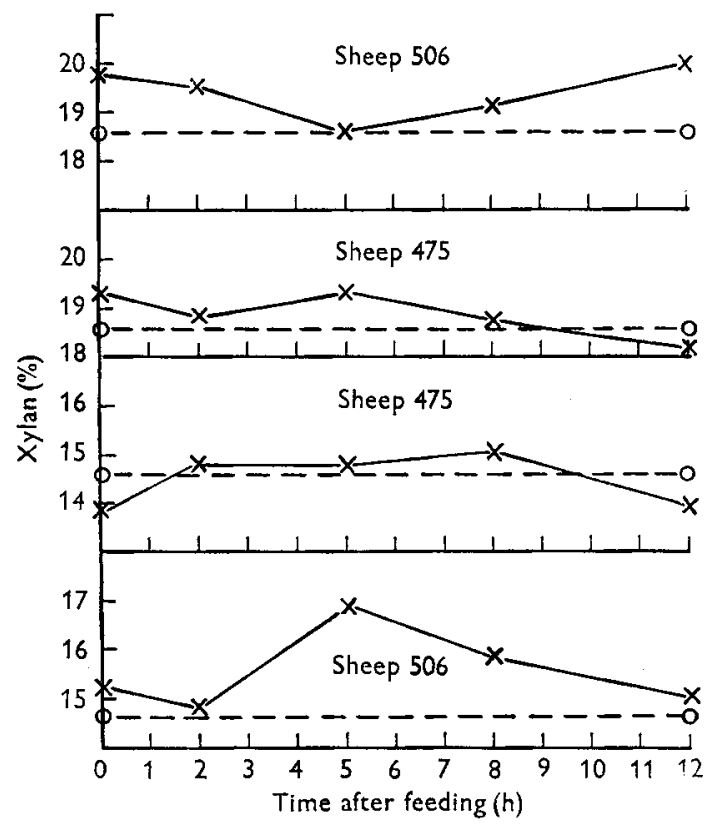

Fig. 2. Percentage of xylan in two samples of hay fed to two sheep, and percentage of xylan in the plant material leaving the abomasum. (Values calculated on a dry, water-extracted basis.) $0_{-}-\mathrm{O}_{\text {, }}$ xylan in the hay fed; $x-\times$, xylan in the material from the abomasum.

strained liquid together with the washings from the plant particles held on the silk. The value varied from 2 to $3 \%$ of the dry matter throughout the $12 \mathrm{~h}$ period. Since the dry sediment constituted $\mathrm{I}-\mathrm{I} \cdot \mathbf{2} \%$ of the original sample taken, and since the plant material itself contained about $18 \%$ xylan, the value of $2-3 \%$ was too small to affect the final result.

\section{DISCUSSION}

The results in Fig. 2 and Table 4, although obtained with only two sheep, show definitely that a substantial quantity of xylose-containing constituents of the diet is fermented in the rumen of the sheep. These values in general agree with those of Marshall (1949) who measured the quantity of furfuraldehyde-yielding substances digested at different levels of the alimentary tract of the sheep.

The difference in the results for the percentage of xylan fermented by the two sheep was probably due to errors arising from the assumptions involved in the 


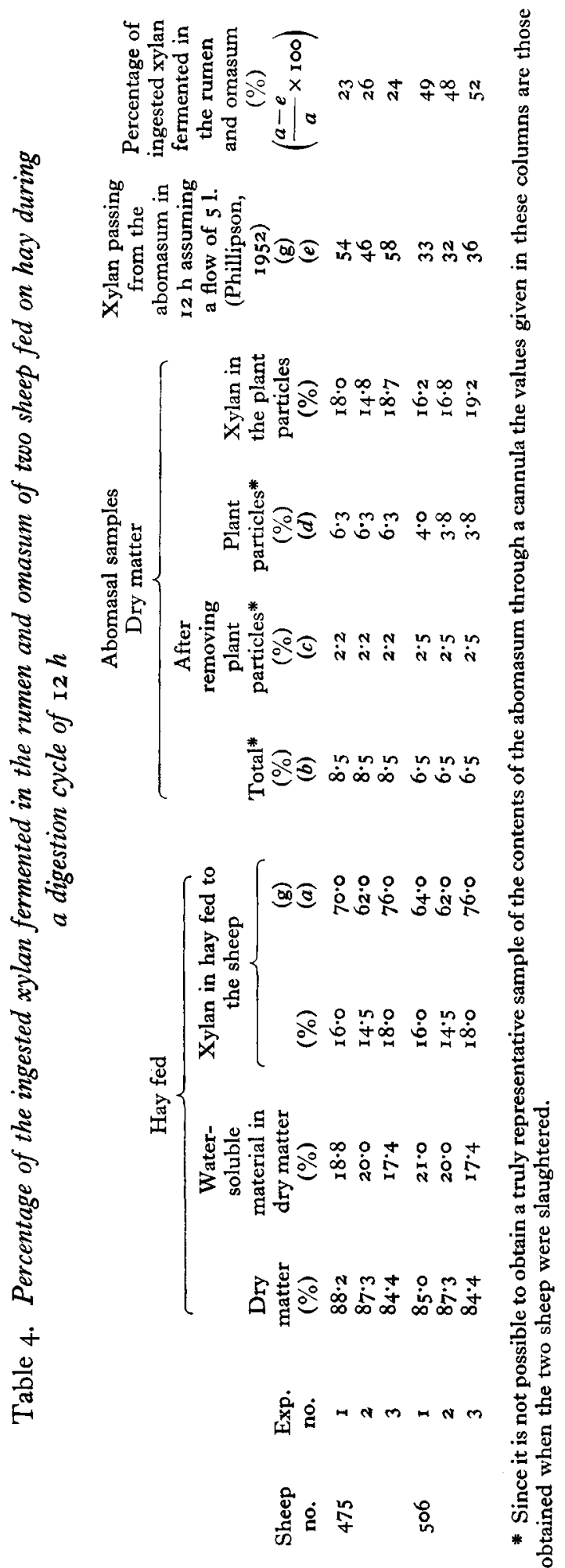


calculation, particularly the assumption that the dry weight of the abomasal contents remained constant when the sheep were fed at a fixed level of food intake. However, assuming that a typical value might be $40 \%$, it is possible to make an approximate calculation of the quantity of xylose-containing substances fermented in the rumen in $24 \mathrm{~h}$. The percentage of pentosans in forage grasses ranges from 9 to 25 with the majority of values between $x 6$ and 20 (Fraps, I930; Buston, 1934; Hallsworth, 1939; Ekelund, 1949). For a sheep at pasture eating in $24 \mathrm{~h}$ rooo $\mathrm{g}$ dry matter containing I6-20\% xylan, the total quantity fermented in the rumen might be $60-80 \mathrm{~g}$.

This quantity is sufficiently large to be of nutritional importance to the sheep and shows that the study of the fermentation of pentosans merits more attention than has hitherto been given to these carbohydrates.

\section{SUMMARY}

By means of a technique involving paper-partition chromatography for the estimation of xylose in hydrolysed samples both of the hay fed and of plant material leaving the abomasum it has been found that the quantity of xylan fed that was fermented in the rumen of sheep fed on hay was $23-26 \%$ in one sheep and $4^{8-52} \%$ in another sheep. The results suggest that in $24 \mathrm{~h}, 60-80 \mathrm{~g}$ xylan may be fermented in the rumen of a sheep at pasture.

The author wishes to thank Dr A. T. Phillipson for fitting the sheep with ruminal and abomasal cannulas.

\section{REFERENCES}

Buston, H. W. (1934). Biochem. F. 28, 1028.

Ekelund, S. (1949). LantbrHögsk. Ann. 16, 179.

Fraps, G. S. (1930). Bull. Tex. agric. Exp. Sta. no. 418.

Gray, F. V. (1947). F. exp. Biol. 24, 15.

Hagedorn, H. C. \& Jensen, B. N. (I923). Biochem. Z. 135, 46.

Hale, E. B., Duncan, C. W. \& Huffman, C. F. (1940). F. Dairy Sci. 23, 953.

Hale, E. B., Duncan, C. W. \& Huffman, C. F. (1947). F. Nutr. 34, 747.

Hallsworth, E. G. (1939). F. Soc. Chem. Ind., Lond., 58, 357.

Heald, P. J. (I95I). Brit. F. Nutr. 5, 75.

Marshail, R. A. (1949). Brit. F. Nutr. 3, I.

Phillipson, A. T. (1952). F. Physiol. I16, 84. 